\title{
DIRETRIZES PROJETUAIS PARA UM ESPAÇO ONDE DUAS GERAÇÕES DISTINTAS PODERÃO TRABALHAR EM CONJUNTO.
}

\author{
Wesley Felipe Lima Antunes, Fabrícia Dias de Moraes Fernandes Borges \\ Universidade do Oeste Paulista - UNOESTE, Curso de Arquitetura e Urbanismo, Presidente Prudente, SP. E- \\ mail: wesleyfelipeantunes@gmail.com
}

\begin{abstract}
RESUMO
O presente trabalho tem por objetivo analisar a maneira que idosos lidam com informatização dos serviços oferecidos à sociedade atual e como isso implica em seu desenvolvimento e autonomia diária. Tendo em mente que as dificuldades dos mesmos de acesso são imensas, por não apresentarem essa vivencia. Através desse ponto de vista, quem poderia contribuir para diminuição dessa dificuldade, seria os adolescentes, nascidos sobre o contexto tecnológico e por assim ser, sua forma de lidar com a tecnologia se faz mais ágil. Partindo desse pensar, proponha-se um projeto arquitetônico que inclua esses dois extremos, jovens e idosos, os nativos e imigrantes digitais dividindo o mesmo espaço. Espaço esse inclusivo situado no município de Presidente Prudente - SP, o qual possa abarcar essas duas gerações que se divergem e mesmo assim, poderão vir a se complementar na aprendizagem, oferecendo apoio tecnológico em um espaço amplo, aberto e funcional.
\end{abstract}

Palavras-chave: Jovens, Idosos, Nativo Digital, Migrante Digital, Tecnológico e Inclusão.

\section{PROJECT GUIDELINES FOR A SPACE WHERE TWO DIFFERENT GENERATIONS CAN WORK IN CONJUNCTION.}

\begin{abstract}
The present study aims to analyze the way elderly people deal with computerization of the services offered to the current society and how this implies in their daily development and autonomy. Keeping in mind that their difficulties of access are immense, because they do not present this experience. From this point of view, who could contribute to reduce this difficulty, would be the adolescents, born on the technological context and so to be, their way of dealing with technology becomes more agile. Starting from this thinking, propose an architectural project that includes these two extremes, young and old, the natives and digital immigrants dividing the same space. This space is located in the municipality of Presidente Prudente - SP, which can encompass these two generations that diverge and even then, may complement each other in learning, offering technological support in a wide, open and functional space.
\end{abstract}

Keywords: Youth, Elderly, Native Digital, Digital Migrant, Technological and Inclusion. 


\section{INTRODUÇÃO}

O presente trabalho tem por objetivo analisar a maneira que idosos lidam com informatização dos serviços oferecidos à sociedade atual e como isso implica em seu desenvolvimento e autonomia diária. Visto que essa população vem de uma cultura onde essa inclusão digital era meramente futurista, observada em filmes com temática tecnológica. Logo presencia-se que atualmente o grande interesse desse público pelas novas tecnologias oferecidas é cada dia maior, contudo as dificuldades de acesso são imensas, por não apresentarem essa vivência.

Partindo desse ponto de vista, quem poderia contribuir para diminuição dessa dificuldade, seria os jovens, nascidos sobre o contexto tecnológico e por assim ser, sua forma de lidar com o mesmo se faz mais ágil, dinâmica e natural. Entendendo esse pensar, é proposto para com esse trabalho um projeto que inclua esses dois extremos, jovens e idosos, os nativos e imigrantes digitais dividindo o mesmo espaço.

Sendo que o jovem como nativo digital, poderá aprender ainda mais, filtrando seu conhecimento e discernindo eticamente suas ações e por ventura, instruir essa população mais velha, os chamados imigrantes digitais, onde os colocarão à par de todas as funcionalidades digitais, desde cursos profissionalizantes à workshops e etc. Dando assim, total autonomia e independência para com os mesmos, logo ambas as gerações poderão disfrutar de um mundo novo ao qual tudo se faz digital e dinâmico.

E para com ambiente inclusivo proposto para o amparo destas duas gerações, este terá consigo espaços amplos e equipados, implantado em um terreno no município de Presidente Prudente - SP, de fácil localidade ao qual envolverá duas gerações que se divergem e mesmo assim, poderão vir a se complementar na aprendizagem, oferecendo apoio tecnológico em um espaço amplo e funcional. Sendo que este projeto fica sendo parte integrante do TCC (Trabalho de Conclusão de Curso), do curso de Arquitetura e Urbanismo da UNOESTE, ainda em desenvolvimento.

\section{METODOLOGIA}

Para a realização desse artigo acadêmico devemos ter como conhecimento que é imprescindível uma metodologia cientifica que possa nos prover com dados que façam referência ao tema proposto, analisando um confrontar ideias e informações, as quais possibilitariam uma ampla discussão, dessa forma atingindo os objetivos propostos nesse projeto acautelado por um levantamento bibliográfico.

Portanto esse projeto também tem a pretensão de propor concomitantemente uma pesquisa qualitativa, pois segundo Rampazzo (2005) a mesma é essencialmente descritiva, possuindo um caráter flexível, o que permite ao pesquisador um correlacionar de ideias.

Ainda que segundo o mesmo, a pesquisa qualitativa advém a priorizar uma coleta de dados, para que essa correlacione ideias, antevendo leituras, imparcialidade na escrita dos resultados, ou seja, o pesquisador deve ser claro e objetivo na conduta de sua pesquisa. Dessa maneira o uso desses recursos metodológico permitirá que a aplicação do nosso projeto consiga os objetivos almejados.

Portanto o desenvolvimento do mesmo será de modo a coletar dados referentes ao contexto e universo do tema, por base de referências bibliográficas e documentais. A necessidade de presenciar o espaço escolhido para o projeto arquitetônico, será de suma importância, onde se poderá entender prioritariamente as condições adversas e favoráveis para com o mesmo e com isso, arquitetar métodos cabíveis para com a forma e assim lidar com tais questões projetuais. Ressaltando que tais métodos serão o resultado de pesquisas 
aludidas aos problemas pertinentes as referências.

A necessidade de presenciar o espaço selecionado para o projeto, será de suma importância, onde se poderá entender prioritariamente as condições adversas e favoráveis para com o mesmo e com isso, arquitetar métodos cabíveis para com a forma e assim lidar com tais questões projetuais. Ressaltando que tais métodos serão o resultado de pesquisas aludidas aos problemas pertinentes.

\section{IMIGRANTE E NATIVO DIGITAL}

Atualmente a sociedade se encontra sobre novas concepções, práticas e ocupações que surgiram decorrente as transformações sociais ligadas diretamente às transformações tecnológicas ao qual a mesma se apropria para se desenvolver e se manter; passando a se ver como Sociedade Midiática, Era Digital ou Era do Computador, ou seja, a sociedade passase a ser denominada a partir dos instrumentos que se utiliza para evoluir (KOHN, MORAIS, 2007).

Tais processos evidenciam a mudança no cenário social da busca pela melhoria e facilidade, que tais formas de se lidar e vivenciar o cotidiano proporcionaria para com a vida dos indivíduos, sendo que o desenvolvimento para com as tecnologias digitais, adaptaria uma dimensão de produtos, forma que se arquiva informações, acesso à informação e a forma de socialização (KOHN, MORAIS, 2007).

Contudo nem todos conseguiram seguir o ritmo desenfreado desse novo desenvolvimento, sendo que na mesma frequência que se cresce essas novas formas de se comunicar e se informar, cresce também a quantidade de jovens e idosos na população, os conhecidos nativos digitais e imigrantes digitais (ALMÊDA; SANTOS, 2017).

Com os avanços da medicina, da farmacologia, as melhorias sanitárias (higiene e saúde), do reconhecimento dos direitos dos idosos e da nova forma de envelhecer, chamada de envelhecimento ativo, a expectativa de vida e crescimento da população idosa tem aumentado consideravelmente, já que tais fatores colaboram com a melhoria da qualidade de vida dessa geração (SOUZA, TAVARES, 2012).

Diante dessas afirmações, faz-se necessário buscar-se de soluções que permitam que o indivíduo idoso envelheça sem perder a conexão com o mundo que o cerca, sendo esse, naturalmente digital e por assim ser, mostra que o conhecimento deve-se ser contínuo (KALEMPA, PETERSEN, PYKOSZ, 2013).

Em contrapartida há quem ande de mãos dadas com essa nova forma de mediática e tecnológica.

Os jovens nascidos a partir de 1998, os conhecidos nativos digitais ou segundo Gobbi, Sakuma, Sousa (apud TAPSCOTT, 2010, p.27), Geração Next ou Geração Z, possuem o verdadeiro domínio dos meios digitais. Essa é a geração em que as redes online são a realidade. Crescendo com a internet consolidada, e com a considerável expansão nos processos comunicativos com a utilização das tecnologias da informação e comunicação. Esses desde pequenos, brincam e interagem, principalmente com dispositivos móveis, além de entenderem o funcionamento dos mais diversos tipos de telas.

Entretanto quais são as expectativas para com esses extremos em uma cultura cada vez mais digital? Voltando a atenção sobre a geração mais velha, os imigrantes digitais, ou seja, envelhecer não precisa significar entregar-se à desocupação.

Quando se chega a terceira idade, o tempo disponível pode ser ocupado de forma prazerosa, buscando-se novos conhecimentos e consequentemente conservando a saúde mental. Sendo que o domínio para com as tecnologias, amplia experiências, amizades e 
horizontes, proporcionando lazer e desafios (KALEMPA, PETERSEN, PYKOSZ, 2013).

Para com o idoso, o Art. 3 do Estatuto do Idoso, viabiliza formas alternativas de participação, ocupação e convívio do mesmo com as demais gerações. Já no Art. 21 , § $1^{\circ}$ garante-se que haja cursos especiais para eles, esses incluirão conteúdo relativo às novas técnicas de comunicação, computação e demais avanços tecnológicos, onde poderão integra-los à vida moderna (SOUZA, TAVARES, 2012).

Portando o mesmo enquanto cidadãos, devem requerer e garantir que sua voz e vontade seja ouvida. Sendo que o Estado deva garanti-lhes recursos, que garantam o ensino das novas tecnologias (inclusão digital). Onde esses possam conseguir exercer sua cidadania, sem anseio de exclusão da sociedade por não acompanharem os avanços tecnológicos; sendo assim, tais políticas de inclusão digital, possibilitam que os próprios usufruam da gama de conhecimentos que a contemporaneidade disponibiliza por meio de revistas, jornais, portais acadêmicos, blogs, bancos e etc (SOUZA, TAVARES, 2012).

Entretendo apesar de serem resguardados pelo Estatuto do Idosos e terem consigo novos recursos que contribuem em seu condicionamento físico e psicológico, o envelhecimento traz declínios agudos ou brandos, sendo esses fisiológicos, sensoriais, cognitivos, emocionais e etc (SOUZA, TAVARES, 2012).

Tais fatores podem ser empecilhos que afetem o acesso dos idosos para com a tecnologia, Tecnologias da Informação e Comunicação (TIC) e Novas Tecnologias de Informação e Comunicação (NTIC); portanto e de suma importância que haja desenvolvidos, interfaces mais acessíveis aos idosos, acatando critérios de ergonomia e usabilidade (SOUZA, TAVARES, 2012).

Já que este ainda utópico conceito de acessibilidade digital se conceba lento, faz-se necessário formas de encaminhar e condicionar o idoso para com a tecnologia. Uma forma predisposta a bons resultados seria a Tecnologia Assistida (TA), para com os idosos que possuem sua mobilidade ou recurso motor comprometido (SOUZA, TAVARES, 2012). E a outra seria a inclusão das TICs e NTICs, levando em conta cada dificuldade individual e por assim ser, apresentar orientações com linguagem simples e explicações direcionadas a cada um (KALEMPA, PETERSEN, PYKOSZ, 2013).

Voltando-se as atenções sobre a geração mais jovem, os nativos digitais ou se preferir, geração Z; segundo Gobbi, Sakuma e Sousa (apud TAPSCOTT, 2010, p.32):

A Geração Internet [...] assiste menos televisão do que seus pais, e o faz de uma maneira diferente. [...] provável que um jovem da Geração Internet ligue o computador e interaja simultaneamente com várias janelas diferentes, fale ao telefone, ouça música, faça o dever de casa, leia uma revista e assista à televisão. A tevê se tornou um a espécie de música de fundo para ele.

Entretanto percebe-se que essa geração não se utiliza de forma benéfica para com os meios tecnológicos, as TICs; o ritmo cada vez mais acelerado, o constante "bombardeio" de informações digitais, acaba a prejudicar e afetar a concentração, atrasando seriamente a capacidade de aprendizado (DAZZI, ENGSTER, PASSERO, 2016).

Porém, com os possíveis problemas que tal mau uso ocasione, muitos autores apegam-se com otimismo, defendendo as TICs, ressaltando que essas são a realidade do mundo contemporâneo e que a sociedade, até mesmo o sistema educacional necessita se adaptar (DAZZI, ENGSTER, PASSERO, 2016).

Contudo o perfil dos jovens alunos que se apresenta para com às salas de aula, o Nativo Digital, possuem interesse em um novo sistema educacional, já que o mesmo se faz analógico, ou seja, a escola se faz ainda muito limitada, não acompanhando o ritmo de 
desenvolvimento da sociedade e advento da tecnologia, logo não usa esses instrumentos a favor da educação (MATOS, ROCHA, 2014).

Diante disso, professores, a escola em si, precisam superar sua prática pedagógica e encontrar respaldo em uma formação efetiva, sem medo de submergir em um meio que para eles, parece desconhecido. Já que os Nativo Digital estão criando uma nova forma de aprender, e com isso cabe ao professor e escola impulsioná-los nesta sociedade (MATOS, ROCHA, 2014).

Logo as gerações anteriores, os chamados imigrantes digitais, passam a caminhar em direção à tecnologia e à internet, de maneira mais lenta sim, entretendo, acudidos pelos próprios nativos digitais neste percurso, ou seja, o processo pelo qual os nativos digitais proporcionam, fez que no âmbito mediático, os jovens contribuam com no processo de ensino para com os idosos, evidenciando sua influência para com as gerações anteriores (GOBBI, SAKUMA, SOUSA, 2015).

Com isso, as diretrizes a serem tomadas para um projeto arquitetônico, onde se propõem a inclusão entre duas gerações, deve ser de forma a seguir objetivos, como o local escolhido que deverá comportar tal tarefa, logo, espaços internos adequados para que haja ensino de qualidade referente a tecnologia. Com isso relacionar por meio dos ambientes a troca de experiências entre os jovens e idosos, os chamados nativos e imigrantes digitais e como essa troca minimizara as diferenças e dificuldades que tais pessoas se encontram.

\section{CONCLUSÃO}

O desenvolvimento deste trabalho, consistiu na interligação de dois extremos (jovem e idoso), a forma que suas vidas eram no passado e quais as suas relações com o contexto que os cercam atualmente, este envolto pela pura tecnologia. Logo, o objetivo de juntar ambos em um espaço que supra necessidades especificas, incluindo e integrando um enquanto ao outro ficando com o desenvolvimento do discernimento na forma que este lida com o meio que domina.

Logo, ao entender estas gerações e seus anseios, a proposta de um projeto arquitetônico, para amparar essa integração, se transformou ao ponto de compreender seu espaço e o local que este projeto será implantado. Com isso a consistência para com os objetivos, conceito e partido, são acolhidos por referências que condicional um melhor entendimento com o aspecto físico e local do projeto, sendo assim, é sugerido volumes que transpareça essa questão da inclusão e a forma que ela deve ser vista, transparente a todos.

Por fim, este projeto fica sendo parte integrante do TCC (Trabalho de Conclusão de Curso), do curso de Arquitetura e Urbanismo da UNOESTE, ainda em desenvolvimento.

\section{REFERÊNCIAS}

ALMÊDA, K. A; SANTOS, R. F. dos. O ENVELHECIMENTO HUMANO E A INCLUSÃO DIGITAL: Análise do Uso das Ferramentas Tecnológicas pelos Idosos. In: NOME DO CONGRESSO, v. 4, 2017. O ENVELHECIMENTO HUMANO E A INCLUSÃO DIGITAL. Maceió: Ci. Inf. Rev., maio/ago. 2017. p. $59-68$.

DAZZI, R. L S; ENGSTER, N. E. W; PASSERO, G. UMA REVISÃO SOBRE O USO DAS TICS NA

EDUCAÇÃo DA GERAÇÃo Z. In: Revista Novas Tecnologias na Educação, v. 14, n² 2, 2017, CINTED-UFRGS. UMA REVISÃO SOBRE O USO DAS TICS NA EDUCAÇÃO DA GERAÇÃO Z... Universidade Federal do Rio Grande do Sul: dezembro. p. 01-08. 
GOBBI, M. C; SAKUMA, A. T; SOUSA, J. F. Migrantes e nativos digitais: câmbio cultural, interação e pertencimento. In: Conferência Brasileira de Mídia Cidadã e V Conferência SulAmericana de Mídia Cidadã, 20, 2015, Bauru-SP. Anais... Bauru-SP: UNESP | FAAC, 22-24 de abril. p. 01-15.

MATOS, E. P. C; ROCHA, A. P. C. DESAFIOS TECNOLÓGICOS FRENTE AOS NATIVOS DIGITAIS. DESAFIOS TECNOLÓGICOS FRENTE AOS NATIVOS DIGITAIS, Florianópolis, v. 3, $\mathrm{n}^{\circ}$. 6 , jul./nov., $2014 . \quad$ Disponível em: <http://incubadora.periodicos.ufsc.br/index.php/IJKEM/article/view/2706>. p.197-209.

PETERSEN, D. A. W; PYKOSZ, L. C; KALEMPA, V. C. Envelhecimento e Inclusão Digital. Inclusão na Terceira Idade, Florianópolis, Santa Catarina, v. 10, $\mathrm{n}^{\circ} 15 ., 1^{\circ}$ semestre., 2013. Disponível em: <http://dx.doi.org/10.5007/1807-0221.2013v10n15p120>. p. 120-128.

RAMPAZZO, Lino. Metodologia Científica para alunos dos cursos de graduação e pósgraduação. 3. ed. São Paulo: Loyola, 2005.

SOUZA, S. T. S. de; TAVARES, M. M. K. Os idosos e as barreiras de acesso às novas tecnologias da informação e comunicação. Revista Novas Tecnologias na Educação, Universidade Federal do Rio Grande do Sul, v.10, n¹, p. 01-07, julho, 2012. Trabalho científico apresentado no NOVAS TECNOLOGIAS NA EDUCAÇÃO, 2012. 